\title{
The Expression Pattern of PDX-1, SHH, Patched and Gli-1 Is Associated with Pathological and Clinical Features in Human Pancreatic Cancer
}

\author{
Karl Quint $^{\mathrm{a}}$ Sebastian Stintzing $^{\mathrm{a}}$ Beate Alinger ${ }^{\mathrm{b}}$ Cornelia Hauser-Kronberger ${ }^{\mathrm{b}}$ \\ Otto Dietze $^{b}$ Susanne Gahr ${ }^{a}$ Eckhart G. Hahn ${ }^{a}$ Matthias Ocker ${ }^{a}$ \\ Daniel Neureiter ${ }^{b}$ \\ a Department of Medicine 1, University Hospital Erlangen, Erlangen, Germany; ${ }^{b}$ Institute of Pathology, \\ Landeskliniken Salzburg, Salzburg, Austria
}

\section{Key Words}

Pancreatic carcinoma $\cdot$ Embryonic markers · Pancreas duodenum homeobox 1 - PDX-1 - Sonic hedgehog $\cdot \mathrm{SHH}$. Survival

\begin{abstract}
Background and Aims: Pancreatic cancer cells have been shown to possess stem-cell-like properties, especially by reactivating embryonic transcription factors involved in tissue differentiation. We therefore investigated if and to what extent developmental genes of the human pancreas are expressed in pancreatic ductal adenocarcinomas and precursor lesions, pancreatic intraepithelial neoplasia (PanIN), and if this correlates or predicts response to treatment and overall survival. Material and Methods: Invasive ductal adenocarcinomas of the pancreas [UICC pT3pNO ( $n=13)$ vs. pT3pN1 $(n=25)]$ and tumors after neoadjuvant chemotherapy [5fluorouracil (FU)/folic-acid and gemcitabine; UICC ypNO ( $\mathrm{n}=$ 7) vs. ypN1 $(n=6)]$ resected between 1997 and 2003 were characterized histochemically and immunohistochemically [pancreas duodenum homeobox 1 (PDX-1), Sonic hedgehog protein (SHH), Patched (Ptc) and Gli-1]. Gene distribution was compared with morphological patterns of the pancreatic carcinoma and PanIN as well as with peritumorous reactions of normal pancreas. Results: The overall expression of PDX-1, $\mathrm{SHH}, \mathrm{Ptc}$ and Gli-1 was low, but showed a distinctive and
\end{abstract}

\section{KARGER}

Fax +4161306 1234 E-Mail karger@karger.ch www.karger.com

\section{(C) 2008 S. Karger AG, Basel and IAP}

1424-3903/09/0092-0116\$26.00/0

Accessible online at:

www.karger.com/pan topographic linkage inside pancreatic carcinomas as well as inside PanINs. Additionally, a topographic and significant association of these markers with nodal status (PDX-1, Ptc, Gli-1), tumor size (PDX-1, Gli-1) and R status (PDX-1) was found. After stratification with the strongest outcome predictor, grading, survival analysis revealed that Ptc expression in grade 2 and PDX-1 expression in grade 3 carcinomas are independent survival factors. Conclusions: Markers of pancreas development are reexpressed in invasive ductal adenocarcinomas and their expression is essentially associated with general clinical and pathological features such as survival or nodal status.

Copyright $\odot 2008$ S. Karger AG, Basel and IAP

\section{Introduction}

Pancreatic carcinoma is one of the most malignant carcinomas, accounting for $6 \%$ of cancer deaths in the Western world. Despite intensive research and recent improvements in patient outcome [1], overall survival remains very poor $[2,3]$. A new approach to elucidate carcinogenesis is to understand organ embryology and to find a possible disarrangement of embryonic morpho-

K.Q., S.S., M.O. and D.N. contributed equally to this work. 
genesis in the context of carcinogenesis $[4,5]$. There is a large body of literature dealing with the expression of pancreas duodenum homeobox 1 (PDX-1) and Sonic hedgehog $(\mathrm{SHH})$ proteins during gastrointestinal development in different species, and various knockout models emphasized the importance of the regulation of these embryological markers during morphogenesis [6-9]. The role of PDX-1 and of members of the hedgehog family such as $\mathrm{SHH}$, the Patched (Ptc) receptor and the transcription factor Gli-1 was pointed out, especially in the pancreas, in the context of endocrine development, regeneration and possible recruitment of stem-cell-like precursor cells during chronic autoimmune and inflammatory destructive pancreatitis [10-14]. Recently, the role of stem cells and reexpression of stem-cell-like factors (e.g. PDX-1 and $\mathrm{SHH}$ ) has been demonstrated during cancer development [15-17]. In this study, we examined if and to what extent and according to what distribution pattern PDX-1, SHH, Ptc and Gli-1 were expressed in human pancreatic ductal cancer (with and without node positivity) and pancreatic intraepithelial neoplasia (PanIN) specimens of a well-defined patient group. Furthermore, we investigated if their presence influences therapeutic responsiveness and overall survival times.

\section{Materials and Methods}

All samples were obtained from the archives of the Department of Pathology of the University of Erlangen-Nuremberg. All tissues were studied in an anonymous fashion, in accordance with the recommendations of the local ethics research committee. Furthermore, the analysis did not extend to examination of individual case records. Only patients with complete follow-up data (including standard risk factors $[18,19])$ were considered. Surgical specimens from patients with invasive ductal adenocarcinoma of the pancreas (UICC pT3 pN0 or pT3pN1) who underwent tumor resection between 1998 and 2004 had been obtained during routine surgery and embedded in paraffin. To assess the role of embryonic differentiation markers on response to neoadjuvant chemotherapy (5-fluorouracil/folic acid and gemcitabine), another group of patients was investigated and analyzed as described.

\section{Immunohistochemistry}

Immunohistochemical staining procedures were applied as described before [20]. 5- $\mu \mathrm{m}$ sections were deparaffinized using graded alcohols. After microwave antigen retrieval (MW) $(10 \mathrm{mmol} / 1$ citrate buffer, $\mathrm{pH} 6.0 ; 8 \mathrm{~min}$ at $560 \mathrm{~W}$ and $8 \mathrm{~min}$ at $800 \mathrm{~W})$ or trypsin, the sections were incubated overnight using antibodies specific for PDX-1 (rabbit polyclonal antibody, dilution 1: 250, MW, Chemicon, Temecula, Calif., USA), SHH (goat polyclonal antibody, 1:100, MW, Santa Cruz Biotechnology, Santa Cruz, Calif., USA), Ptc (goat polyclonal antibody, 1:100, trypsin, Santa Cruz Biotechnology), Gli-1 (goat polyclonal antibody, 1:200, MW, Santa Cruz Biotechnology), Ki-67 (mouse monoclo- nal antibody, 1:500, MW, Dako, Glostrup, Denmark) and p53 (mouse monoclonal antibody, 1:1,000, MW, Dako). Next, depending on the primary antibody, biotinylated rabbit-anti-goat or goat-anti-rabbit (Dako) antibodies were applied on the sections. Detection was done using Dako's streptavidin-biotin complex and alkaline phosphatase system, following their user's manual. The sections were developed using Fast Red (Sigma, Germany) or diaminobenzidine (DAB; Roche Molecular Biochemicals, Mannheim, Germany). Nuclei were counterstained with hematoxylin.

\section{Morphological Pattern Analysis and Quantization of Stained Material}

The stained sections were viewed by a blinded independent pathologist and representative images were taken from 4 highpower fields ( $400 \times$ magnification) in each section. Intensity of expression levels was characterized using the following scheme: negative $(-)$, weak $(+)$, moderate $(++)$, strong $(+++)$, differing focal expression being indicated in round brackets. Additionally, the percentage of positive cells per high-power field was determined using ImageAccess Enterprise 5 software (Imagic Bildverarbeitung, Glattbrugg, Switzerland). For further statistical analysis, the calculated product of intensity and extensity was used. The distribution of PDX-1, SHH, Gli-1, and Ptc was compared with the morphological patterns of the pancreatic carcinoma (separately for tumor front and tumor center) and PanIN as well as with reactive response of normal pancreatic tissue [21,22]. Because of the small size of PanIN lesions, only intensity measurement was statistically analyzed for PanIN. Although many heterogeneous target genes of PDX-1 and of members of the hedgehog family were described, most of them are associated with cell cycle or cell growth and death [23-25]. Therefore, we investigated the expression extensity of Ki-67 and p53 in the front and center areas of the tumor.

\section{Statistical Analysis}

For univariate analysis between different subgroups, the MannWhitney U test was used. Correlation coefficients were calculated according to Pearson and Kendall. Patient survival was estimated by the Kaplan-Meier method comparing the survival curves with the log-rank test; the correlation of sets of variables was determined in a multivariate analysis with the Cox proportional hazards model [26]. All tests were two-tailed. A p value of less than 0.05 was considered statistically significant. All statistical analyses were performed using SPSS 14 (SPSS Inc., Chicago, Ill., USA).

\section{Results}

\section{Analysis of the General Pathologic Features}

Patients' main characteristics are listed in table 1. In short, the pT3pN0, pT3pN1, ypTypn0 and ypTypN1 groups consisted of 13, 25, 7 and 6 patients, respectively. Patient populations in the nonchemotherapy groups (node-positive vs. node-negative) were adequately matched and did not show any statistically significant differences in gender, age, R status and tumor size. Grading was significantly higher in node-positive (G2/G3 = 
Table 1. Basic patient characteristics

\begin{tabular}{|c|c|c|c|c|c|}
\hline Group & $\begin{array}{l}\text { Age } \\
\text { years }\end{array}$ & $\begin{array}{l}\text { Sex } \\
\mathrm{m} \\
\mathrm{f}\end{array}$ & $\begin{array}{l}\text { Grading } \\
\text { G1 } \\
\text { G2 } \\
\text { G3 }\end{array}$ & $\begin{array}{l}\text { Tumor size } \\
\mathrm{mm}\end{array}$ & $\begin{array}{l}\text { Residual tumor } \\
\text { R0 } \\
\text { R1 } \\
\text { R2 }\end{array}$ \\
\hline pT3 pN0 $(n=13)$ & $66.4 \pm 8.4$ & $\begin{array}{l}8(61.5 \%) \\
5(38.5 \%)\end{array}$ & $\begin{aligned} 0 & (0.0 \%) \\
10 & (76.9 \%), p<0.05 \\
3 & (23.1 \%), p<0.05\end{aligned}$ & $28.3 \pm 15.8$ & $\begin{array}{c}12(92.3 \%) \\
0(0.0 \%) \\
1(7.7 \%)\end{array}$ \\
\hline pT3 pN1 $(n=25)$ & $61.9 \pm 10.8$ & $\begin{array}{l}11(44.0 \%) \\
14(56.0 \%)\end{array}$ & $\begin{array}{c}0(0.0 \%) \\
10(40.0 \%), p<0.05 \\
15(60.0 \%), p<0.05\end{array}$ & $28.5 \pm 14.8$ & $\begin{array}{c}20(80.0 \%) \\
3(12.0 \%) \\
2(8.0 \%)\end{array}$ \\
\hline ypT ypN0 $(\mathrm{n}=7)$ & $60.6 \pm 7.7$ & $\begin{array}{l}6(85.7 \%) \\
1(14.3 \%)\end{array}$ & $\begin{array}{l}0(0.0 \%) \\
5(71.4 \%) \\
2(28.6 \%)\end{array}$ & $26.4 \pm 8.0$ & $\begin{array}{l}7(100.0 \%) \\
0(0.0 \%) \\
0(0.0 \%)\end{array}$ \\
\hline ypT ypN1 $(n=6)$ & $63.5 \pm 5.9$ & $\begin{array}{l}3(50.0 \%) \\
3(50.0 \%)\end{array}$ & $\begin{array}{l}0(0.0 \%) \\
4(66.7 \%) \\
2(33.3 \%)\end{array}$ & $24.1 \pm 9.7$ & $\begin{array}{l}5(83.3 \%) \\
1(16.7 \%) \\
0(0.0 \%)\end{array}$ \\
\hline
\end{tabular}

10/15) compared to node-negative patients (G2/G3 = 10/3; $\chi^{2}$ test, $\left.\mathrm{p}<0.05\right)$.

\section{Distribution Pattern of PDX-1- and}

Hedgehog-Expression Depending on

Nodal Status and Preoperative Chemotherapy

Overall, the mean expression rate of all investigated proteins was weak and the highest expression was observed for PDX-1 compared to proteins of the hedgehog signaling cascade. In detail, the expression level of PDX-1 in the tumor front was significantly lower in the pT3N0 sections than in $\mathrm{pT} 3 \mathrm{~N} 1$ sections; it was also significantly higher in the tumor center of pT3N0 than pT3N1 sections (Mann-Whitney U test, $\mathrm{p}<0.05$; table 2). SHH expression was low and statistically independent of nodal status or localization inside the tumor. Similarly, Ptc and Gli-1 expression was low but significantly higher at the tumor front (Ptc/Gli-1) and tumor center (Gli-1) in the pT3N1 sections than pT3N0 (see table 2). In the ypN0/ypN1 sections, the expression of all embryonic markers was significantly lower (negative to very low) compared to the nontreated group (Mann-Whitney U test, $\mathrm{p}<0.05$ ) with the higher expression levels of PDX-1 comparable to those of the nontreated group. Interestingly, no signal of $\mathrm{SHH}$, Ptc and Gli-1 was observed in the tumor center of ypN0/ $\mathrm{pN} 1$ sections. Compared to the expression of PDX-1, SHH, Ptc and Gli-1, the extensity of Ki-67 and p53 was continuously higher at the tumor front than in the tumor center, independent of the pretreatment status (table 2) with significantly higher levels in the nontreated compared to the treated group (Mann-Whitney $\mathrm{U}$ test, $\mathrm{p}<$ 0.05). In relation to morphologic structures, expression of PDX-1 was found to be distinctive and to be present to a greater extent in ductal tumor formations than in solid formations (fig. 1,2), whereas PDX-1 could be detected in periductal cancer cells as well as in single dissociated tumor cells at the tumor front (fig. 1), especially in grade 3 pancreatic carcinomas (fig. 2B). Additionally, PDX-1 and Ki-67 expression was co-localized at the tumor front (fig. 2B, C). In all tumors only some tumor cells at the invasion front showed positivity for $\mathrm{SHH}$, Ptc or Gli-1 (fig. 1, 2E, F). Especially in the tumor center of grade 2 pancreatic carcinomas, Ptc expression was linked to dilated ductal tumor formation with focal coexpression of Gli-1 (fig. 2G, H, M, N) and with strong expression of p53 (fig. 2P-R). In adjacent non-tumorous tissue, upregulation of PDX-1 and SHH could be observed in areas of extended pancreatic fibrosis and atrophy, whereas in normal pancreas primarily endocrine cells express PDX-1 as well as SHH, Ptc or Gli-1 as internal control (fig. 1).

\section{Correlation Analysis of PDX-1 and Hedgehog}

Signaling Cascade with General Pathologic Features

Correlation analysis revealed a significant negative correlation between PDX-1 expression at the tumor center and nodal status $(\mathrm{r}=-0.641, \mathrm{p}<0.001)$ and a significant positive correlation with tumor size $(r=0.499, \mathrm{p}<0.001)$ in patients not treated with chemotherapy. On the other 
Table 2. Distribution pattern of PDX-1 and SHH depending on nodal status and preoperative chemotherapy - evaluation of intensity and extensity levels as well as calculated product of PDX-1, SHH, Ptc and Gli-1 in comparison to extensity of Ki67 and p53 at the tumor front and center

\begin{tabular}{|c|c|c|c|c|c|}
\hline & & \multicolumn{4}{|c|}{$\begin{array}{l}\text { Intensity }{ }^{1} / \text { extensity }{ }^{2} \text { and the calculated expression product }{ }^{3} \text { of the markers at the tumor front (tf) and } \\
\text { center (tc) in dependence of nodal status and pre-operative chemotherapy }\end{array}$} \\
\hline & & pT3 pN0 & pT3 pN1 & ypNo & ypN1 \\
\hline PDX-1 & $\begin{array}{l}\mathrm{TF} \\
\mathrm{TC}\end{array}$ & $\begin{aligned} 1.1 & \pm 0.3 / 13.1 \pm 0.9^{*} \\
14.7 & \pm 5.5^{*} \\
2.1 & \pm 0.6 / 15.6 \pm 0.8^{*} \\
33.4 & \pm 11.2^{*}\end{aligned}$ & $\begin{aligned} 1.4 & \pm 0.5 / 13.6 \pm 1.0 \\
20.3 & \pm 7.8 \\
1.3 & \pm 0.4 / 13.4 \pm 1.1 \\
18.1 & \pm 7.7\end{aligned}$ & $\begin{array}{l}0.6 \pm 0.5 / 6.6 \pm 1.5^{*} \\
4.1 \pm 3.8^{*} \\
1.4 \pm 0.5 / 13.8 \pm 1.1 \\
19.8 \pm 9.3\end{array}$ & $\begin{aligned} 1.3 & \pm 0.5 / 13.0 \pm 1.5 \\
18.3 & \pm 10.1 \\
1.3 & \pm 0.5 / 13.5 \pm 1.3 \\
17.3 & \pm 5.8\end{aligned}$ \\
\hline SHH & $\begin{array}{l}\mathrm{TF} \\
\mathrm{TC}\end{array}$ & $\begin{array}{l}0.6 \pm 0.5 / 8.3 \pm 1.0 \\
5.1 \pm 4.3 \\
0.2 \pm 0.4 / 5.1 \pm 1.1 \\
1.2 \pm 2.1\end{array}$ & $\begin{array}{l}0.5 \pm 0.5 / 6.8 \pm 1.5 \\
3.7 \pm 3.6 \\
0.3 \pm 0.4 / 3.8 \pm 0.8 \\
1.1 \pm 1.8\end{array}$ & $\begin{array}{l}0.5 \pm 0.7 / 6.2 \pm 2.0 \\
4.1 \pm 6.6 \\
\text { n.d./n.d. } \\
\text { n.c. }\end{array}$ & $\begin{array}{l}0.6 \pm 0.5 / 6.6 \pm 2.0 \\
3.9 \pm 3.9 \\
\text { n.d./n.d. } \\
\text { n.c. }\end{array}$ \\
\hline Ptc & $\begin{array}{l}\mathrm{TF} \\
\mathrm{TC}\end{array}$ & $\begin{array}{l}0.4 \pm 0.5 / 4.1 \pm 0.8^{*} \\
1.7 \pm 2.1^{*} \\
0.5 \pm 0.5 / 5.2 \pm 1.2 \\
2.7 \pm 2.7\end{array}$ & $\begin{array}{l}0.9 \pm 0.2 / 7.6 \pm 1.3 \\
7.0 \pm 2.4 \\
0.7 \pm 0.4 / 5.8 \pm 0.5 \\
4.1 \pm 2.7\end{array}$ & $\begin{array}{l}0.6 \pm 0.5 / 3.3 \pm 0.5 \\
1.9 \pm 1.8 \\
\text { n.d./n.d. } \\
\text { n.c. }\end{array}$ & $\begin{array}{l}0.3 \pm 0.5 / 3.2 \pm 0.8 \\
0.9 \pm 1.7 \\
\text { n.d./n.d. } \\
\text { n.c. }\end{array}$ \\
\hline Gli-1 & $\begin{array}{l}\mathrm{TF} \\
\mathrm{TC}\end{array}$ & $\begin{array}{l}0.1 \pm 0.3 / 2.2 \pm 0.5^{*} \\
0.2 \pm 0.6^{*} \\
0.2 \pm 0.4 / 5.9 \pm 1.0^{*} \\
1.2 \pm 2.4^{*}\end{array}$ & $\begin{array}{l}0.8 \pm 0.3 / 6.9 \pm 0.7 \\
5.9 \pm 2.6 \\
0.6 \pm 0.4 / 5.3 \pm 0.6 \\
3.3 \pm 2.7\end{array}$ & $\begin{array}{l}\text { n.d./n.d. } \\
\text { n.c. } \\
\text { n.d./n.d. } \\
\text { n.c. }\end{array}$ & $\begin{array}{l}0.3 \pm 0.5 / 3.1 \pm 0.9 \\
0.9 \pm 1.6 \\
\text { n.d./n.d. } \\
\text { n.c. }\end{array}$ \\
\hline $\mathrm{Ki}-67^{4}$ & $\begin{array}{l}\mathrm{TF} \\
\mathrm{TC}\end{array}$ & $\begin{array}{l}27.8 \pm 8.5 \\
20.1 \pm 5.7\end{array}$ & $\begin{array}{l}27.5 \pm 7.4 \\
20.6 \pm 7.8\end{array}$ & $\begin{array}{r}13.1 \pm 3.6 \\
9.1 \pm 3.1\end{array}$ & $\begin{array}{r}14.2 \pm 2.6 \\
8.3 \pm 3.2\end{array}$ \\
\hline p5 $53^{4}$ & $\begin{array}{l}\text { TF } \\
\text { TC }\end{array}$ & $\begin{array}{l}20.6 \pm 11.8 \\
16.0 \pm 10.3\end{array}$ & $\begin{array}{l}23.2 \pm 16.8 \\
12.8 \pm 7.6\end{array}$ & $\begin{array}{l}8.3 \pm 3.5 \\
3.6 \pm 0.5\end{array}$ & $\begin{array}{l}7.3 \pm 2.0 \\
4.1 \pm 2.2\end{array}$ \\
\hline
\end{tabular}

\footnotetext{
${ }^{*} \mathrm{p}<0.05$. n.d. $=$ Not detected; n.c. $=$ not calculated.

${ }^{1}$ Semiquantitative evaluation of the stainings: negative (0), weak (+ or 1), moderate $(++$ or 2$)$ and strong $(+++$ or 3$)$.

${ }^{2}$ Quantitative evaluation of the stainings (mean $\%$ of all cancer cells at 4 different high-power fields per tumour specimen).

${ }^{3}$ Calculated expression product: intensity $\cdot$ extensity.

${ }^{4}$ For Ki-67 and p53 the extensity was measured by mean $\%$ of all cancer cells at 4 different high-power fields per tumour speci-
} men.

hand, a significant positive correlation was established between PDX-1 expression at the tumor front and grading as well as R status $(\mathrm{r}>0.771, \mathrm{p}<0.05)$ and PDX-1 expression in the tumor center and tumor size $(r=0.713, p<$ 0.05 ) in chemotherapy-treated patients. In the hedgehog signaling cascade, a significant positive correlation was found between Ptc and Gli-1 expression at the tumor front and nodal status in patients not treated with chemotherapy $(r>0.760, p<0.01)$. Additionally, expression of Ptc at the tumor front was significantly associated with tumor size in chemotherapy-treated patients $(\mathrm{r}=0.818, \mathrm{p}<0.05)$. Compared to the extensity of Ki-67 and p53, we found a significant association of PDX-1 expression with Ki-67 at the tumor front and with p53 at the tumor center $(r>$
$0.478, \mathrm{p}<0.05)$ as well as of Gli-1 expression with p53 at the tumor center $(\mathrm{r}=0.518, \mathrm{p}=0.04)$, whereas SHH and Ptc were usually $(p>0.05)$ linked to expression of Ki-67 and p53. Interestingly, besides a significant positive association of Ki67 at the tumor center with tumor size ( $\mathrm{r}=$ $0.597, p=0.03$ ), other pathological features only tended to be positively linked to the expression of Ki-67 and p53.

\section{Correlation of Gene Expression Levels with Grade of \\ PanINs}

Overall, the expression of all proteins correlated significantly with the grade of PanINs (Spearman's correlation analysis, $r>0.98, p<0.01$ ). The expression levels were comparable with the invasive tumor compartments: 


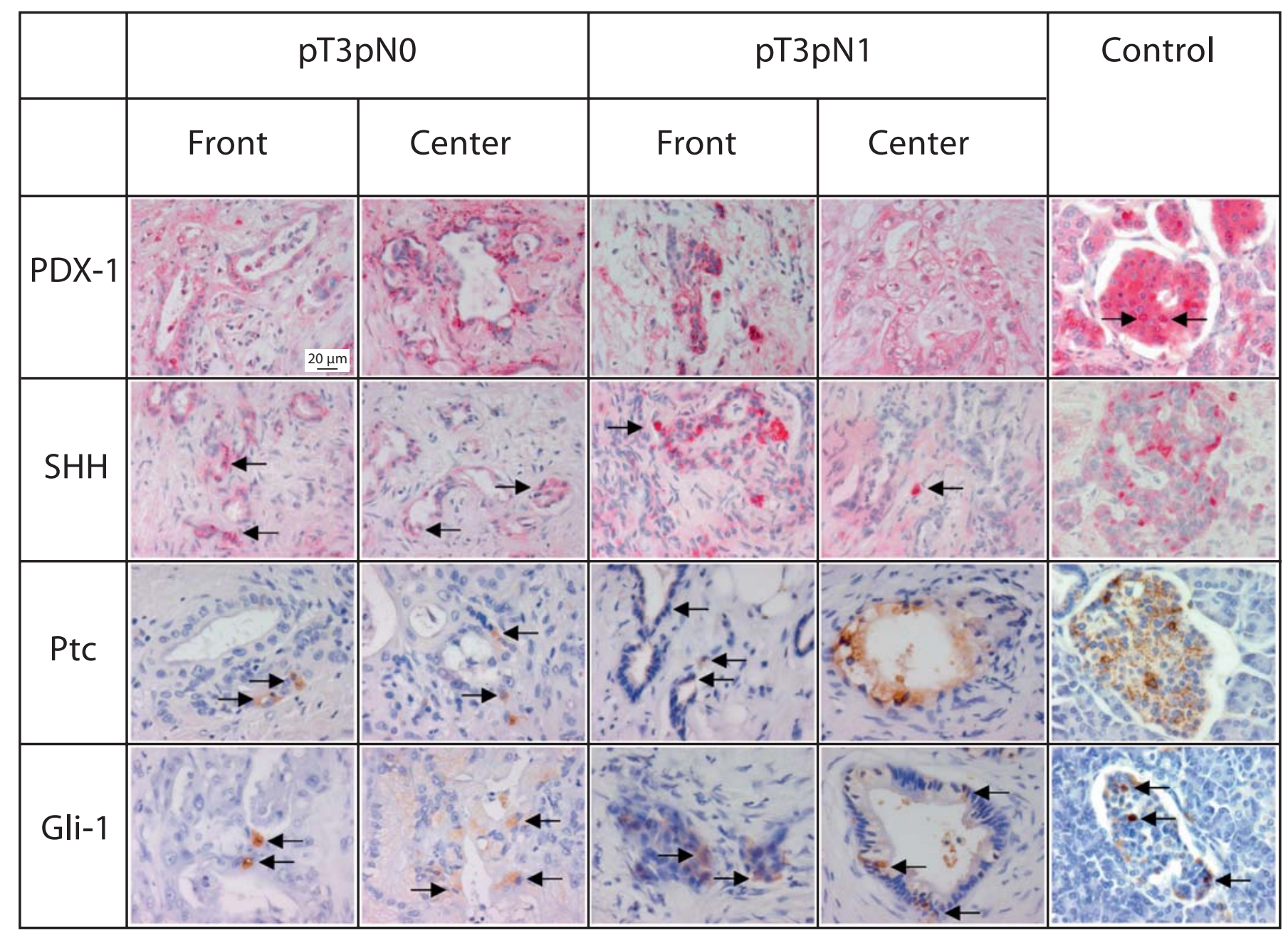

Fig. 1. Typical immunohistochemical patterns of PDX-1, SHH, Ptc and Gli-1 in pancreatic cancer in dependence of nodal status: overall, independent of the nodal status, higher expression of PDX-1 was observed compared to all other markers of the hedgehog signaling pathway. PDX-1 was mainly detected in ductal tumor formations in the tumor center. The expression of $\mathrm{SHH}$ was low and predominantly located in disseminated ductal forma- tions or single tumor cells at the tumor front (see arrows). Ptc and Gli-1 were mainly found in single tumor cells (see arrows), especially of node-positive cases. As an internal control, endocrine cells inside the islets of Langerhans of normal pancreas showed typical expression of PDX-1, SHH, Ptc and Gli-1, focally with nuclear expression (see arrows) (magnification of all figures: $400 \times)$.
Fig. 2. Representative immunohistochemical expression pattern of PDX-1, Ptc and Gli-1 in consecutive specimens depending on localization and grading of pancreatic carcinoma. Typical expression of PDX-1 at the tumor front $(\mathbf{B}, 200 \times)$ in a G3 pancreas carcinoma specimen with predominant solid tumor formations (square) (A, HE, 12.5×). PDX-1 was detected inside and around ductal tumor structures with mainly cytoplasmic but focally intranuclear localization (B, arrows). The corresponding tumor area revealed enhanced proliferative activity using immunohistochemistry for Ki-67 (C, $200 \times)$. Inside indicated areas of a G2/G3 pancreas carcinoma specimen with ductal/solid tumor formations at the tumor front (D, square, HE, 12.5×) and tumor center (D, dotted square, HE, 12.5×) Ptc and Gli-1 were expressed only very sparsely at the tumor front in single cells (E, Ptc, arrows,
$200 \times$; F, Gli-1, arrow, $200 \times$ ) and enhanced at the tumor center especially inside dilated tumor ductal structures (G, Ptc, 200×; H, Gli-1, 200×). Representative areas of a G2 pancreas carcinoma specimen at the tumor front (I, square, HE, 12.5X) and tumor center (I, dotted square,) HE, $12.5 \times$ ) in comparison to the expression of Ptc (J, tumor front, 200×; M, tumor center, 200×), Gli-1 (K, tumor front, 200×; N, tumor center, 200X) and PDX-1 (L, tumor front, $200 \times$; O, tumor center, $200 \times$ ). Ptc and Gli-1 were predominantly expressed at the tumor center $(\mathbf{M}, \mathbf{N})$ whereas PDX-1 was found at the tumor front, predominantly in association with ductal tumor formations (L). Expression of Ptc (P, 400×) and Gli$1(\mathbf{Q}, 400 \times$, arrows) in typical ductal tumor formation at the tumor center (of $\mathbf{I}$, dotted square) was associated with strong expression of p53 (R, $400 \times)$. 

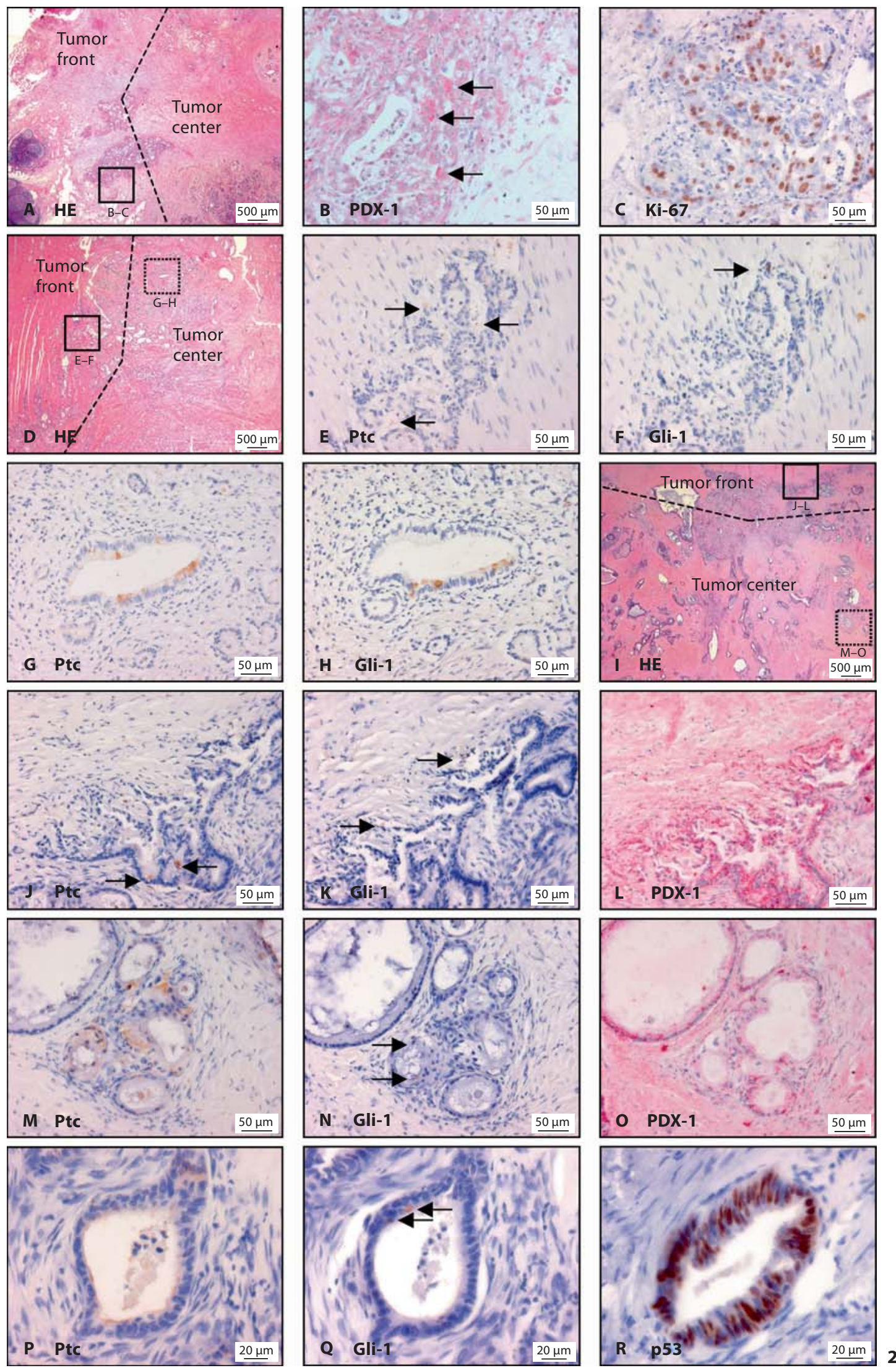
The expression of PDX-1 was significantly higher than those of the members of the hedgehog signaling cascade $\left(\chi^{2}\right.$ test, $\left.\mathrm{p}<0.05\right)$. In detail, expression levels of PDX-1 continuously increased from low expression in PanIN-1A and $-1 \mathrm{~B}$ to moderate in PanIN-2 and high in PanIN-3 lesions (fig. 3) with no significant dependence on the nodal state $\left(\chi^{2}\right.$ test, $\left.p>0.05\right)$. No expression of SHH, Ptc and Gli-1 was found in PanIN-1A and -1B lesions, whereas low expression was seen in lesions of PanIN-2 (SHH: 0.24 \pm 0.43, Ptc: $0.22 \pm 0.42$ and Gli 1: $0.06 \pm 0.25)$ and PanIN-3 (SHH: $0.24 \pm 0.49$, Ptc: $0.19 \pm 0.40$ and Gli-1: $0.16 \pm 0.37)$. No significant difference was found between the node-positive and the node-negative group $\left(\chi^{2}\right.$ test, $p>0.05)$. A correlation analysis of protein expression in PanINs with general pathologic findings as well as protein expression in the invasive compartments of the carcinoma revealed a positive association with protein expression in the invasive carcinoma independent of the location, but the association did not reach significance.

\section{Survival Time Analysis}

The mean expression rate of PDX-1, Shh, Ptc and Gli-1 as well as of Ki-67 and p53 in tumor center and front was calculated for further time-dependent statistical analysis and divided into low and high expression rates according to mean expression level. Age, sex, grading, nodal status (N0 versus $\mathrm{N} 1$ ), tumor size, $\mathrm{R}$ status and preoperative chemotherapy were used for the Cox-regression analysis. Only grading was identified as a factor significantly influencing survival (Wald $\chi_{\text {d.f. }=1}^{2}=3.987$, hazard ratio 2.645, confidence interval: 0.916-7.641, $\mathrm{p}=0.05$ ) (fig. 4A). The expression patterns of the analyzed proteins did not additionally influence patient survival. Therefore, a stratification of the patients according to tumor grading was done. Using this model, the Kaplan-Meier analysis identified the expression of PDX-1 at the tumor front in the grade 3 subgroup and Ptc expression in the tumor center of the grade 2 subgroup as predictive prognostic factors. PDX-1 expression at the tumor front had a significant negative influence on survival in grade 3 pancreatic carcinomas (Logistic Rank Test (Mantel Cox) $\mathrm{p}=0.05$; fig. 4C), whereas higher expression of Ptc at the tumor center was associated with better outcome in grade 2 pancreatic carcinomas (Logistic Rank Test (Mantel Cox) $p=0.03$; fig. 4B, C). All additionally performed sum scores of PDX-1, SHH, Ptc and Gli-1 as well as of Ki-67 and p53 had no significant impact on the survival time. This was also evident for the expression of these proteins in PanINs also in circumstances of recoding in low and high expression.

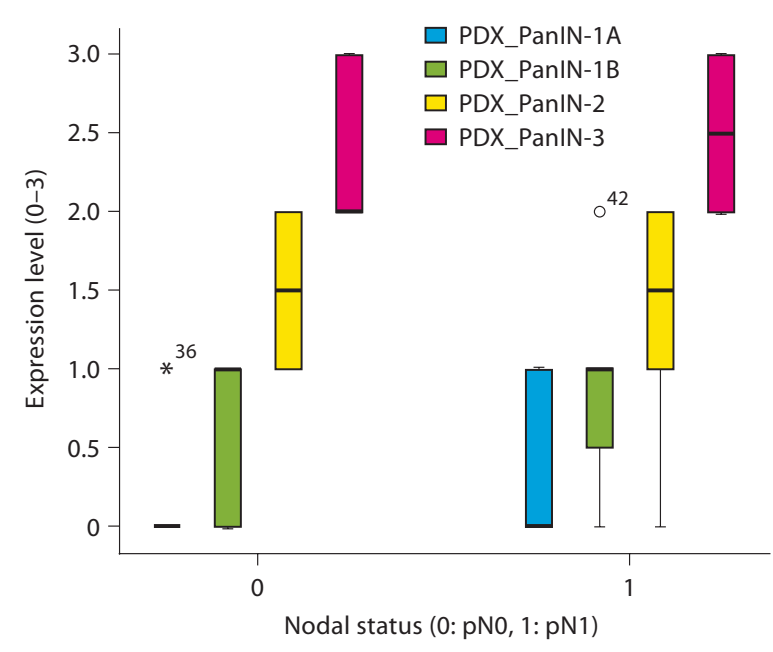

Fig. 3. Distribution pattern of PDX-1 and hedgehog proteins, depending on the grade of PanINs.

\section{Discussion}

The main findings of our investigation are summarized as follows: (1) PDX-1 as well as proteins of the hedgehog signaling cascade such as $\mathrm{SHH}$, Ptc and Gli-1 were found in low to moderate amounts in pancreatic carcinomas. (2) Additionally, these markers were found in linear (PDX-1) and nonlinear (hedgehog) expression patterns in precancerous lesions of PanINs. (3) The expression of these embryological markers was clearly associated with pathological and clinical features (nodal status, tumor size and pre-operative treatment. (4) Finally, classical grading influenced survival of the patients with pancreas carcinoma. Using statistical stratification with grading, single protein expression of PDX-1 or Ptc could be identified as a possible predictive survival marker.

Our study complemented what was already known about the expression of embryonic markers like PDX-1, $\mathrm{SHH}, \mathrm{Ptc}$ and Gli-1 in pancreatic cancer and its precursor lesions [15-17]. We have shown the exact expression levels at different localizations within the tumor, i.e. enhanced expression of these markers in ductal tumor formations (assessed separately for tumor front and center) and in adjacent fibrotic and atrophic tissue. Mainly PDX1 and to a lower extent SHH, Ptc and Gli-1 were detected in the human pancreatic carcinoma specimens. In contrast to the linear PDX-1 expression inside PanINs, hedgehog family members showed a stepwise black-or- 

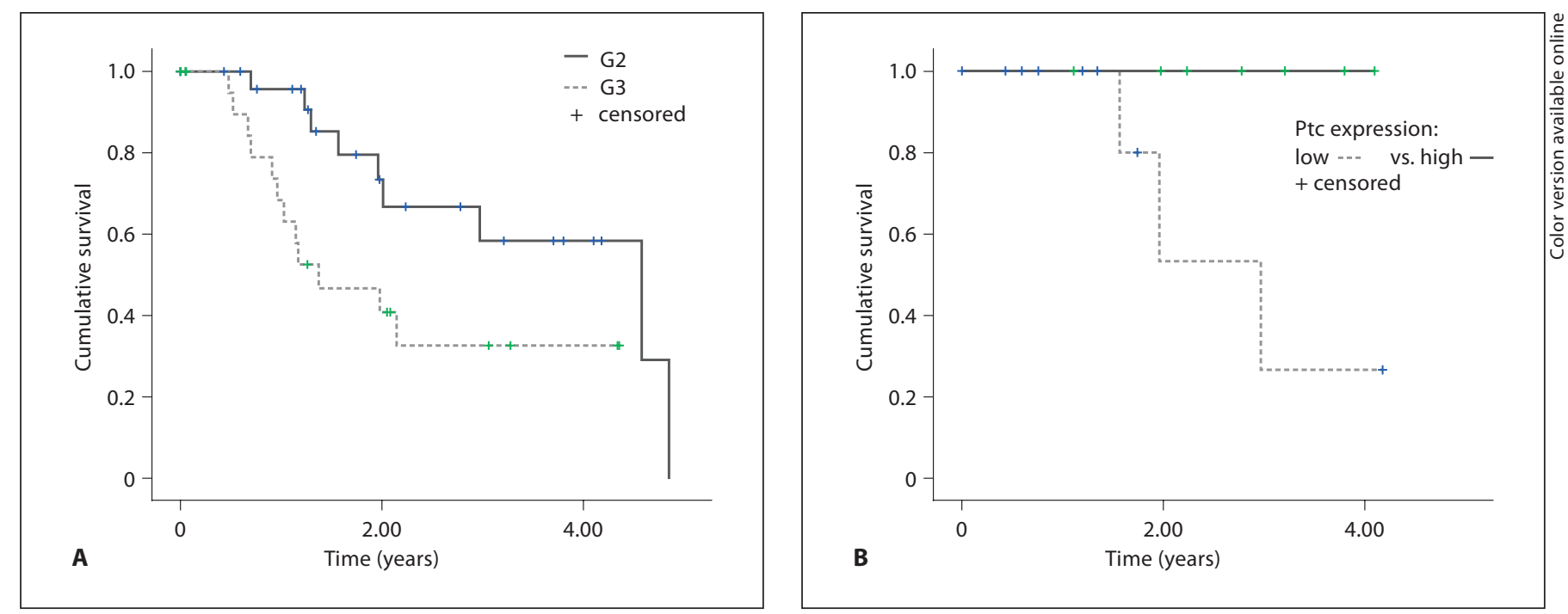

Fig. 4. Kaplan-Meier curves were performed to investigate the patient survival. A Patient survival rates depending on grading. B Patient survival rates depending on expression of Ptc at the tumor center in cases with grade 2 pancreatic cancer. $\mathbf{C}$ Patient survival rates depending on expression of PDX-1 at the tumor front in cases with grade 3 pancreatic cancer.

white expression pattern comparable to findings in intraductal papillary mucinous tumors, which are putative pancreatic cancer precursor lesions, too [27]. This indicates that embryonic markers of morphogenesis are associated with the grade and progression of PanINs similarly to classical markers of proliferation and differentiation [28]. Interestingly, the expression pattern was heterogeneous in invasive carcinomas: we found a higher expression of hedgehog members (especially Ptc) at the tumor front and in the center in nontreated nodal-positive cases than in nontreated nodal-negative cases. In contrast, the distribution of PDX-1 was the same as that of the hedgehog proteins at the tumor front but differed in the tumor center. Although Gli proteins are known

nuclear transcription factors, they are also part of the cytoplasmic signal transduction pathway of SHH via its membranous receptor Ptc and the Smoothend (SMO) regulator [29], which is in line with our results showing (predominant) cytoplasmic and nuclear expression of Gli-1. While the regulation of cytoplasmic to nucleus shuttling is well described for the Drosophila homologue of Gli, cubitus interruptus (Ci), this mechanism is not completely understood in vertebrates [30]. In the cytoplasm and in the absence of SHH, Gli usually forms a complex with several regulatory protein kinases, e.g. Fused (Fu), Suppressor of Fused (Sufu) and others like protein kinase A (PKA), glycogen synthase kinase 3 (GSK3) or casein kinase 1 (CK1) [31], indicating that Gli 
has more functions in pancreatic carcinogenesis than just mediating the hedgehog signaling pathway (for a detailed review, see [14]). Our results show an overall low activity of the SHH pathway, especially in the tumor center, which explains the predominant cytoplasmic staining of Gli-1 in these cases. During embryonic development, $\mathrm{SHH}$ repression in the foregut endoderm leads to the activation of the homeobox transcription factor PDX-1 in the pancreatic bud [32]. While PDX-1 expression is restricted to $\beta$-cells in the normal adult pancreas, reactivation can occur by inflammation, regeneration and tumor formation already in early precursor lesions like PanIN [33]. Several studies have shown that PDX-1 is expressed in up to 50\% of pancreatic ductal adenocarcinomas and correlated with staging, lymph node status, proliferation index and prognosis $[34,35]$. Although a nuclear expression of the transcription factor PDX-1 has been repeatedly demonstrated in pancreatic $\beta$-cells, we and others found a predominant cytoplasmic localization in the investigated pancreatic ductal adenocarcinomas. In endocrine cells, the nucleo-cytoplasmatic translocation of PDX-1 has been shown to be regulated by glucose metabolism, oxidative stress and subsequent activation of the c-Jun $\mathrm{N}$ terminal kinase (JNK) pathway [36, 37]. Interestingly, gemcitabine, which was included in the standard chemotherapy regimen of our patients, has been shown to induce apoptosis also via the JNK pathway $[38,39]$ and may thus contribute to the cytoplasmic localization of PDX-1 found in our study. Other factors regulating the nuclear translocation of PDX-1 include signaling through phosphatidylinositol 3-kinase (PI3K) [40, 41] or posttranscriptional modifications as ubiquitination or sumoylation [42], which have not yet been confirmed in clinical specimens of pancreatic ductal adenocarcinoma. We previously identified two major morphologic and molecular pathways in human pancreatic cancer cell lines using xenograft models: A ductal tumor pattern with predominance of CK7 and PDX-1 and a more differentiated solid tumor pattern with increased expression of CK8 and SHH/Ptc [43]. As our patients were treated for invasive ductal adenocarcioma, we expected and confirmed a ductal morphology with low levels of SHH but with higher levels of PDX-1. Additionally, the expression levels of hedgehog proteins like SHH, Ptc and Gli-1 was reduced under preoperative chemotherapy as in our own epigenetic studies, indicating the relevance of analyzing the expression pattern of these embryonic markers for further therapeutic interventions [44]. Looking in detail at tumor compartments, previous studies have shown that proliferation, which occurs predominantly at the tumor front, is dependent on $\mathrm{SHH}$ expression in pancreas cancer [35]. In vitro experiments demonstrated that downregulation of the hedgehog pathway through siRNA or cyclopamine is essentially associated with a strongly reduced proliferation activity $[17,45]$. These observations were made in other types of human cancer as well. In colorectal adenocarcinoma, $\mathrm{SHH}$ and the expression of its downstream signaling components Gli-1 and FOXM1 were markedly increased compared to normal colonic tissue [46]. The same findings could be confirmed in the colon adenocarcinoma-derived cell line HT-29: Here, exogenic $\mathrm{SHH}$ stimulation increased proliferation and was abrogated by treatment with cyclopamine or specific anti-SHH-antibodies. This further exemplifies that a subset of cells (i.e. SHH-positive cells) at the tumor front might be responsible for proliferation and invasion of the tumor and possesses early developmental or stem-celllike properties [47]. Another study identified a subtype of cells in pancreatic cancer termed 'pancreatic cancer stem cells' for their ability of self-renewal, of producing differentiated progeny and increased expression of the developmental signaling molecule $\mathrm{SHH}$, properties usually shared with stem cells [48]. These findings suggest that the capability of a tumor to grow and propagate is dependent on this stem-cell-like subtype within the tumor itself. The number of these subsets of cells, which are positive for the surface markers CD44, CD24 and ESA is quantified at $0.2-0.8 \%$ of the total pancreatic cancer cells. SHH expression in this subset of cells was upregulated 46-fold compared to normal pancreatic epithelial cells, while SHH expression in bulk pancreatic cancer cells was upregulated 4-fold compared to normal pancreatic epithelial cells. It is therefore possible that the increased expression of $\mathrm{SHH}$ at only some cells at the tumor front in our samples could be attributed to this subset of pancreatic cancer cells. Using microarray investigations, it was shown that the gene and protein expression pattern depends significantly on the localization inside pancreatic cancer [49]. Our results showed that a higher proliferation index (determined by Ki-67 immunohistochemistry) is found at the tumor front and in chemotherapy-naive specimens and that $\mathrm{Ki}-67$ is strongly associated with PDX-1 expression at this location. Our results thus confirm findings in ovarian carcinomas showing a positive association between cell proliferation (as measured by Ki-67 positivity) in vivo and embryonic marker gene expression [50]. Interestingly, p53 expression was also associated with Ki-67 expression at both sites and with both PDX-1 and Gli- 1 only at the tumor center. These findings indicate differential roles of $\mathrm{p} 53$ during pancreatic cancer 
formation and progression; further studies are needed to address this issue.

Our findings show a differential association of the investigated markers with the patients' clinico-pathological features. While nodal-negative cases are associated with PDX-1, nodal-positive cases are linked to Ptc and Gli-1 expression, indicating that different molecular mechanism of embryonic markers are involved in the development of nodal metastasis. Interestingly, another investigation found a completely different association of PDX-1 expression and nodal status which could be caused by the heterogeneous patient group (e.g. all UICC stages) as well as by the fact that we analyzed the whole and not the topographical expression pattern inside pancreatic tumors [35]. Using a survival analysis, classical grading was a negative predictor of outcome [18]. Interestingly, after stratification with grading, PDX-1 and Ptc were also predictors of outcome. Especially the negative predictorPDX-1 is comparable to earlier findings. Koizumi et al. [34] showed that the survival of PDX-1-positive patients was poorer than that of PDX-1-negative patients On the other hand, upregulation of the hedgehog ligand receptor
Ptc could be identified as a positive predictive marker of patient outcome and was in line with the study of Liu et al. [51] showing reduced expression in cases with poorly differentiated cancer. Taken together, these findings support that morphologic and molecular patterning inside of the heterogeneous tumor compartments is involved in tumor progression and clinical outcome. Although we investigated a relatively homogeneous group of invasive ductal adenocarcinomas of the pancreas in our study, the findings must be considered with caution considering the small number of patients (especially of pretreated cases), which limits the power of our study. Additional prospective studies are needed to confirm our findings and establish these embryonic marker genes as potential new biomarkers of pancreatic cancer.

\section{Acknowledgements}

The excellent technical assistance of Andrea Hartl and Sandra Leitner is gratefully acknowledged. This work was supported by a grant of the Johannes and Frieda Marohn-Foundation.

\section{References}

1 Riall TS, Nealon WH, Goodwin JS, Zhang D, Kuo YF, Townsend CM Jr, Freeman JL: Pancreatic cancer in the general population: improvements in survival over the last decade. J Gastrointest Surg 2006;10:1212-1223.

2 Carpelan-Holmstrom M, Nordling S, Pukkala E, Sankila R, Luttges J, Kloppel G, Haglund C: Does anyone survive pancreatic ductal adenocarcinoma? A nationwide study re-evaluating the data of the Finnish Cancer Registry. Gut 2005;54:385-387.

3 Jemal A, Murray T, Ward E, Samuels A, Tiwari RC, Ghafoor A, Feuer EJ, Thun MJ: Cancer statistics, 2005. CA Cancer J Clin 2005;55:10-30.

4 Beachy PA, Karhadkar SS, Berman DM: Tissue repair and stem cell renewal in carcinogenesis. Nature 2004;432:324-331.

5 Neureiter D, Herold C, Ocker M: Gastrointestinal cancer - only a deregulation of stem cell differentiation? (Review). Int J Mol Med 2006;483-489.

6 Jensen J: Gene regulatory factors in pancreatic development. Dev Dyn 2004;229:176200.

7 Hui H, Perfetti R: Pancreas duodenum homeobox-1 regulates pancreas development during embryogenesis and islet cell function in adulthood. Eur J Endocrinol 2002;146: 129-141.
8 Chuong CM, Patel N, Lin J, Jung HS, Widelitz RB: Sonic hedgehog signaling pathway in vertebrate epithelial appendage morphogenesis: perspectives in development and evolution. Cell Mol Life Sci 2000;57:16721681.

9 Hebrok M, Kim SK, St Jacques B, McMahon AP, Melton DA: Regulation of pancreas development by hedgehog signaling. Development 2000;127:4905-4913.

10 Kayed H, Kleeff J, Keleg S, Buchler MW, Friess H: Distribution of Indian hedgehog and its receptors patched and smoothened in human chronic pancreatitis. J Endocrinol 2003;178:467-478.

11 Sharma A, Zangen DH, Reitz P, Taneja M, Lissauer ME, Miller CP, Weir GC, Habener JF, Bonner-Weir S: The homeodomain protein IDX-1 increases after an early burst of proliferation during pancreatic regeneration. Diabetes 1999;48:507-513.

12 Ashizawa S, Brunicardi FC, Wang XP: PDX1 and the pancreas. Pancreas 2004;28:109120.

13 Nielsen CM, Williams J, van den Brink GR, Lauwers GY, Roberts DJ: Hh pathway expression in human gut tissues and in inflammatory gut diseases. Lab Invest 2004;84: $1631-1642$
14 Fernandez-Zapico ME: Primers on molecular pathways GLI: more than just Hedgehog? Pancreatology 2008;8:227-229.

15 Thayer SP, Di Magliano MP, Heiser PW, Nielsen CM, Roberts DJ, Lauwers GY, Qi YP, Gysin S, Fernandez-Del Castillo C, Yajnik V, Antoniu B, McMahon M, Warshaw AL, Hebrok M: Hedgehog is an early and late mediator of pancreatic cancer tumorigenesis. Nature 2003;425:851-856.

16 Berman DM, Karhadkar SS, Maitra A, Montes DO, Gerstenblith MR, Briggs K, Parker AR, Shimada Y, Eshleman JR, Watkins DN, Beachy PA: Widespread requirement for Hedgehog ligand stimulation in growth of digestive tract tumours. Nature 2003;425: 846-851.

17 Kayed H, Kleeff J, Keleg S, Guo J, Ketterer K, Berberat PO, Giese N, Esposito I, Giese T, Buchler MW, Friess H: Indian hedgehog signaling pathway: expression and regulation in pancreatic cancer. Int J Cancer 2004;110: 668-676.

18 Monkemuller K, Fry LC, Malfertheiner P: Pancreatic cancer is 'always non-resectable'. Dig Dis 2007;25:285-288. 
19 Pawlik TM, Gleisner AL, Cameron JL, Winter JM, Assumpcao L, Lillemoe KD, Wolfgang C, Hruban RH, Schulick RD, Yeo CJ, Choti MA: Prognostic relevance of lymph node ratio following pancreaticoduodenectomy for pancreatic cancer. Surgery 2007; 141:610-618.

20 Neureiter D, Heuschmann P, Stintzing S, Kolominsky-Rabas P, Barbera L, Jung A, Ocker M, Maass M, Faller G, Kirchner T: Detection of Chlamydia pneumoniae but not of Helicobacter pylori in symptomatic atherosclerotic carotids associated with enhanced serum antibodies, inflammation and apoptosis rate. Atherosclerosis 2003;168:153162.

21 Luttges J, Schemm S, Vogel I, Hedderich J, Kremer B, Kloppel G: The grade of pancreatic ductal carcinoma is an independent prognostic factor and is superior to the immunohistochemical assessment of proliferation. J Pathol 2000;191:154-161.

22 Hruban RH, Takaori K, Klimstra DS, Adsay NV, Albores-Saavedra J, Biankin AV, Biankin SA, Compton C, Fukushima N, Furukawa T, Goggins M, Kato Y, Kloppel G, Longnecker DS, Luttges J, Maitra A, Offerhaus GJ, Shimizu M, Yonezawa S: An illustrated consensus on the classification of pancreatic intraepithelial neoplasia and intraductal papillary mucinous neoplasms. Am J Surg Pathol 2004;28:977-987.

23 Keller DM, McWeeney S, Arsenlis A, Drouin J, Wright CV, Wang H, Wollheim CB, White P, Kaestner KH, Goodman RH: Characterization of pancreatic transcription factor $\mathrm{Pdx}-1$ binding sites using promoter microarray and serial analysis of chromatin occupancy. J Biol Chem 2007;282:32084-32092.

24 Eichberger T, Sander V, Schnidar H, Regl G, Kasper M, Schmid C, Plamberger S, Kaser A, Aberger F, Frischauf AM: Overlapping and distinct transcriptional regulator properties of the GLI1 and GLI2 oncogenes. Genomics 2006;87:616-632.

25 Kasper M, Schnidar H, Neill GW, Hanneder M, Klingler S, Blaas L, Schmid C, HauserKronberger C, Regl G, Philpott MP, Aberger F: Selective modulation of Hedgehog/GLI target gene expression by epidermal growth factor signaling in human keratinocytes. Mol Cell Biol 2006;26:6283-6298.

26 Aigner T, Müller S, Neureiter D, Illstrup DM, Kirchner T, Björnsson J: Prognostic relevance of cell biologic and biochemical features in conventional chondrosarcomas. Cancer 2002;94:2273-2281.

27 Jang KT, Lee KT, Lee JG, Choi SH, Heo JS, Choi DW, Ahn G: Immunohistochemical expression of Sonic hedgehog in intraductal papillary mucinous tumor of the pancreas. Appl Immunohistochem Mol Morphol 2007; 15:294-298.
28 Maitra A, Adsay NV, Argani P, IacobuzioDonahue C, De Marzo A, Cameron JL, Yeo CJ, Hruban RH: Multicomponent analysis of the pancreatic adenocarcinoma progression model using a pancreatic intraepithelial neoplasia tissue microarray. Mod Pathol 2003; 16:902-912.

29 Kasper M, Regl G, Frischauf AM, Aberger F: GLI transcription factors: mediators of oncogenic Hedgehog signalling. Eur J Cancer 2006;42:437-445.

30 Sisson BE, Ziegenhorn SL, Holmgren RA Regulation of $\mathrm{Ci}$ and $\mathrm{Su}(\mathrm{fu})$ nuclear import in Drosophila. Dev Biol 2006;294:258-270.

31 Kogerman P, Grimm T, Kogerman L, Krause D, Unden AB, Sandstedt B, Toftgard R, Zaphiropoulos PG: Mammalian suppressorof-fused modulates nuclear-cytoplasmic shuttling of Gli-1. Nat Cell Biol 1999;1:312319.

32 Offield MF, Jetton TL, Labosky PA, Ray M, Stein RW, Magnuson MA, Hogan BL, Wright CV: PDX-1 is required for pancreatic outgrowth and differentiation of the rostral duodenum. Development 1996;122:983-995.

33 Hezel AF, Kimmelman AC, Stanger BZ Bardeesy N, DePinho RA: Genetics and biology of pancreatic ductal adenocarcinoma. Genes Dev 2006;20:1218-1249.

34 Koizumi M, Doi R, Toyoda E, Masui T, Tulachan SS, Kawaguchi Y, Fujimoto K, Gittes GK, Imamura M: Increased PDX-1 expression is associated with outcome in patients with pancreatic cancer. Surgery 2003;134: 260-266.

35 Liu T, Gou SM, Wang CY, Wu HS, Xiong JX, Zhou F: Pancreas duodenal homeobox-1 expression and significance in pancreatic cancer. World J Gastroenterol 2007;13:26152618.

36 Kawamori D, Kajimoto Y, Kaneto H, Umayahara Y, Fujitani $\mathrm{Y}$, Miyatsuka T, Watada $\mathrm{H}$ Leibiger IB, Yamasaki Y, Hori M: Oxidative stress induces nucleo-cytoplasmic translocation of pancreatic transcription factor PDX-1 through activation of c-Jun NH(2)terminal kinase. Diabetes 2003;52:28962904.

37 Kaneto H, Miyatsuka T, Kawamori D, Matsuoka TA: Pleiotropic roles of PDX-1 in the pancreas. Rev Diabet Stud 2007;4:209-225.

38 Habiro A, Tanno S, Koizumi K, Izawa T, Nakano Y, Osanai M, Mizukami Y, Okumura T, Kohgo Y: Involvement of p38 mitogen-activated protein kinase in gemcitabine-induced apoptosis in human pancreatic cancer cells. Biochem Biophys Res Commun 2004;316: 71-77.

39 Teraishi F, Zhang L, Guo W, Dong F, Davis JJ, Lin A, Fang B: Activation of c-Jun NH2terminal kinase is required for gemcitabine's cytotoxic effect in human lung cancer H1299 cells. FEBS Lett 2005;579:6681-6687.

40 Elrick LJ, Docherty K: Phosphorylationdependent nucleocytoplasmic shuttling of pancreatic duodenal homeobox-1. Diabetes 2001;50:2244-2252.
41 Rafiq I, da Silva Xavier G, Hooper S, Rutter GA: Glucose-stimulated preproinsulin gene expression and nuclear trans-location of pancreatic duodenum homeobox-1 require activation of phosphatidylinositol 3-kinase but not p38 MAPK/SAPK2. J Biol Chem 2000;275:15977-15984.

42 Kishi A, Nakamura T, Nishio Y, Maegawa H, Kashiwagi A: Sumoylation of $\mathrm{Pdx} 1$ is associated with its nuclear localization and insulin gene activation. Am J Physiol Endocrinol Metab 2003;284:E830-E840.

43 Neureiter D, Zopf S, Dimmler A, Stintzing S, Hahn EG, Kirchner T, Herold C, Ocker M: Different capabilities of morphological pattern formation and its association with the expression of differentiation markers in a xenograft model of human pancreatic cancer cell lines. Pancreatology 2005;5:387-397.

44 Neureiter D, Zopf S, Leu T, Dietze O, HauserKronberger C, Hahn EG, Herold C, Ocker M: Apoptosis, proliferation and differentiation patterns are influenced by Zebularine and SAHA in pancreatic cancer models. Scand J Gastroenterol 2007;42:103-116.

45 Nakashima H, Nakamura M, Yamaguchi $H$, Yamanaka N, Akiyoshi T, Koga K, Yamaguchi K, Tsuneyoshi M, Tanaka M, Katano M: Nuclear factor-kappaB contributes to hedgehog signaling pathway activation through sonic hedgehog induction in pancreatic cancer. Cancer Res 2006;66:7041-7049.

46 Douard R, Moutereau S, Pernet P, Chimingqi M, Allory Y, Manivet P, Conti M, Vaubourdolle M, Cugnenc PH, Loric S: Sonic Hedgehog-dependent proliferation in a series of patients with colorectal cancer. Surgery 2006; 139:665-670.

47 Jeong S, Lee DH, Lee JI, Lee JW, Kwon KS, Kim PS, Kim HG, Shin YW, Kim YS, Kim YB: Expression of Ki-67, p53, and K-ras in chronic pancreatitis and pancreatic ductal adenocarcinoma. World J Gastroenterol 2005; 11:6765-6769.

48 Li C, Heidt DG, Dalerba P, Burant CF, Zhang L, Adsay V, Wicha M, Clarke MF, Simeone DM: Identification of pancreatic cancer stem cells. Cancer Res 2007;67:1030-1037.

49 Nakamura T, Kuwai T, Kitadai Y, Sasaki T, Fan D, Coombes KR, Kim SJ, Fidler IJ: Zonal heterogeneity for gene expression in human pancreatic carcinoma. Cancer Res 2007;67: 7597-7604.

50 Chen X, Horiuchi A, Kikuchi N, Osada R, Yoshida J, Shiozawa T, Konishi I: Hedgehog signal pathway is activated in ovarian carcinomas, correlating with cell proliferation: its inhibition leads to growth suppression and apoptosis. Cancer Sci 2007;98:68-76.

51 Liu MS, Yang PY, Yeh TS: Sonic hedgehog signaling pathway in pancreatic cystic neoplasms and ductal adenocarcinoma. Pancreas $2007 ; 34: 340-346$. 